\title{
Photographic Media for Pain Expression: Situated Learning with Graduate-Entry Masters Students to Develop Skills in Applying Theory-to-Practice
}

\author{
Cary A. Brown, Mary-Lou Halabi, Kristen MacDonald, Lorena Campbell, \\ Robyn Guenette \\ Faculty of Rehabilitation Medicine, Department of Occupational Therapy, University of Alberta, \\ Edmonton, Canada. \\ Email: cary.brown@ualberta.ca \\ Received March 28 ${ }^{\text {th }}$, 2011; revised April 20 ${ }^{\text {th }}$, 2011; accepted May $10^{\text {th }}, 2011$.
}

\begin{abstract}
Entry-level healthcare practitioners must be able to engage in critical thinking, life long learning and be autonomous and accountable within the complex demands of healthcare in the 21st century. However, structuring learning opportunities to foster these skills within the pre-qualification curriculum can be challenging. To-date, little evidence exists in the literature to guide educators. This case report discusses how an elective module in the therapeutic use of digital photography for Master of Science in occupational therapy (MScOT) students was designed to enable students to develop an appreciation for, and ability in, scholarship and the application of theory-informed practice. The elective module is used as an example to illustrate the potential and relevance for Social Learning theory, Situated Learning theory and the concept of Most Knowledgeable Other (MKO) to guide capacity building in scholarship and theory-based practice. This collaboratively written student/faculty theoretical perspective, incorporating anecdotal evidence extracted from students' learning assignments in the module, supports our conclusion that these types of learning modules may offer a useful vehicle in which situated learning can occur.
\end{abstract}

Keywords: Situated Learning, Social Learning Theory, Occupational Therapy Students

\section{Introduction}

In 2009, the American Occupational Therapy Association (AOTA) issued a position statement on Scholarship in Occupational Therapy, highlighting that therapists have successfully embraced scholarly practice built on being reflective practitioners (Rolfe, Freshwater, \& Jasper, 2001; Schon, 1983) who identify, critique and engage with the evidence-base (AOTA, 2009). AOTA goes on to point out that scholarly practice alone is insufficient and that scholarship is also required. Scholarship, as defined by AOTA, is the "knowledge resulting from study and research in a particular field" (AOTA, 2009: p. 791). This distinction between scholarly practice and scholarship is intriguing and we hope, through this theoretical perspective paper, to advance the discussion within the occupational therapy profession.

The value occupational therapy practitioners hold for scholarship and the theory-driven research that scholarship requires is less clearly demonstrated than the profession's valuing of evidence-based practice. Contemporary occupational therapy theorists propose that practitioners question the relevance of theoretical concepts to day-to-day practice. These theorists propose that occupational therapists do not universally embrace the importance of scholarship as a mechanism to drive practice forward (Hammel, Finlayson, Kielhofner, Helfrich, \& Peterson, 2002; Kielhofner, 2005). And yet, the ability to build practice on a clearly articulated evidence-base is now, more than ever before, the hallmark of competent practice (Ikiugu, Smallfield,
\& Condit, 2009). To create evidence we must first articulate the theories and models we will be testing. As the Canadian Association of Occupational Therapists (CAOT) points out, entry-level practitioners need skills that go beyond technical abilities; they must also be able to engage in critical thinking, life long learning, and be autonomous, accountable practitioners within the complex demands of healthcare in the $21^{\text {st }}$ century (CAOT, n.d).

\section{Objective}

This theoretical perspective article will discuss how an elective module in the therapeutic use of digital photography for graduate entry Master of Science in Occupational Therapy (MScOT) students was designed in such a way that enabled students to develop an appreciation for, and ability in, scholarship and the application of theory-informed practice. The first author was the instructor and the four co-authors were students in the elective. The decision to write about the experience and to include the students' reflections was prompted by the quality of the student written work submitted for assessment and the consistently positive feedback about the module.

\section{Background: The Relevance of Social Learning Theory}

Social Learning theory, as proposed by the Russian psychologist Vygotsky (Wertsch \& Sohmer, 1995), assumes that we learn through working with others on common tasks and challenges. From these interactions and relationships, we ac- 
quire knowledge that may be generalized across other settings. The learner becomes an active participant in the generation of this knowledge. Wertsch and Sohmer (1995) comment that Vygotsky's Social Learning theory conceptualized that persons who are perceived to have a better understanding or skill related to the presenting task, (what he called the "More Knowledgeable Others" (MKOs), will strongly influence the understanding each learner constructs. How MKOs come to be perceived by an individual learner to be either better informed or more skillful in a given task is influenced by both social beliefs and personal experience. In the case of many occupational therapy students, fieldwork preceptors and other practicing occupational therapists they meet during their studies hold MKO roles.

Fieldwork placements are experiential learning, where students, often for the first time, actually witness what an occupational therapist does. From this perspective then, it follows that the students' experiences of active problem solving, within an applied context that promotes a positive relationship with a $\mathrm{MKO}$, have a strong potential to be more powerful learning experiences than purely scholarly learning based on theoretical and abstract problem solving activities. Using Social Learning theory, we can appreciate why students place high value on techniques and skills acquired during clinical fieldwork placements. However, this becomes problematic when experiential learning is privileged over both the evidence-based and theory-informed practice students are exposed to in the often decontextualized academic class-room setting.

A review of the occupational therapy education literature shows that how students acquire an appreciation for scholarship and theory informed practice is an under-studied area. After some preliminary interest in the topic in the late 1970's-early 1980's (Reed, 1984; Shapiro \& Shanahan, 1976; Van Deusen, 1986), there has been little research to guide those interested in refining curriculum to better address the need for future clinicians to develop deeper scholarship and value for theory-informed practice. We did find one seminal report written by a team of occupational therapy educators and researchers who addressed the challenge through curriculum design (Hammell et al. 2002) based on principles of situated learning (Knowledgebase, 2009). Stein (1998) defines situated learning as creating an environment where adult students deal with situations within the uncertainty and complexity of the lived experience. He proposes that "participants will create their own knowledge out of the raw materials of experience, i.e., the relationships with other participants, the activities, the environmental cues, and the social organization that the community develops and maintains" (Stein, 1998).

\section{Creating a Situated Learning Opportunity}

The MScOT program requires students to take one-credit elective modules that focus on content beyond the expected entry-to-practice competencies. The first author used this opportunity to design a module with a visiting artist. In this module, students would develop skills in using digital photography as an expressive media for communicating pain. Digital photography as therapeutic media for pain self-expression has been used successfully in outcome studies (Padfield \& Hurwitz, 2003; Padfield, Janmohamed, Zakrzewska, Pither, \& Hurwitz, 2010) and we had the unique opportunity to have the lead author/artist in these studies as a guest facilitator on the module.
Our objectives were for students to develop:

- an understanding for the therapeutic potential of the activity;

- a deep appreciation of the demands placed on patients by this activity, and;

- an ability to carryout a theory-based activity analysis (Crepeau, 2003) from two different theoretical perspectives applied to the same activity.

This final goal of a theory-based activity analysis we saw as a vehicle to help students deepen their appreciation for the value of theory-informed practice and the scholarship of practice.

\section{Module Description}

The module was delivered over two days and ran for eight hour each day. There were several short didactic lectures to set the context and give background to the issues that make pain difficult for patients to communicate. However, for the most part, students were immersed in exploring a physical pain experience of their own and problem-solving how to represent that pain pictorially. Students were asked to think of a past experience (for example a toothache, migraine, or fractured limb) before the module started and then to bring a digital camera and any objects that might help represent their pain into the module on the first day. Some students chose to focus on depicting an emotional pain instead of a physical event. All students were cautioned to select experiences they were comfortable sharing with others and both instructors regularly checked with students about comfort levels.

The students worked in pairs but also frequently made use of others individuals in the module to seek assistance with object positioning challenges and with technological questions related to the cameras and picture editing software. Most of the students used Picasa ${ }^{\circledR}$ which is freely available on the internet (http://picasa.google.com/). Students were free to use the available classrooms and lab space as well as any interior or exterior public areas around the building. Examples of the images created during the module are seen in Figures 1 and 2.

Applying Stein's definition of situated learning (Stein, 1998), the elements we needed to design into the module included:

- uncertainty and complexity;

- the need to relate to other participants;

- and to create a sense of "community" which could be maintained, at some level, over time.

Some of the strategies we used to achieve these objectives are outlined below.

We created an environment immersing students in an experiential learning activity (eight hours a day for two days on a weekend). This brought the students together as a group, “a community" with a bond unique from the one they shared with their classmates in the program in general. Uncertainty and complexity were introduced at a number of levels. From a pragmatic perspective, the module had never run before so students had no knowledge of what to expect from talking with their classmates, the artist and the university faculty member had not worked together before, and the artist was from another country and not known to any of the students.

There was uncertainty as well as students made decisions about what lived pain experience they wished to draw upon as they acquired a new skill and explored how they wished to 


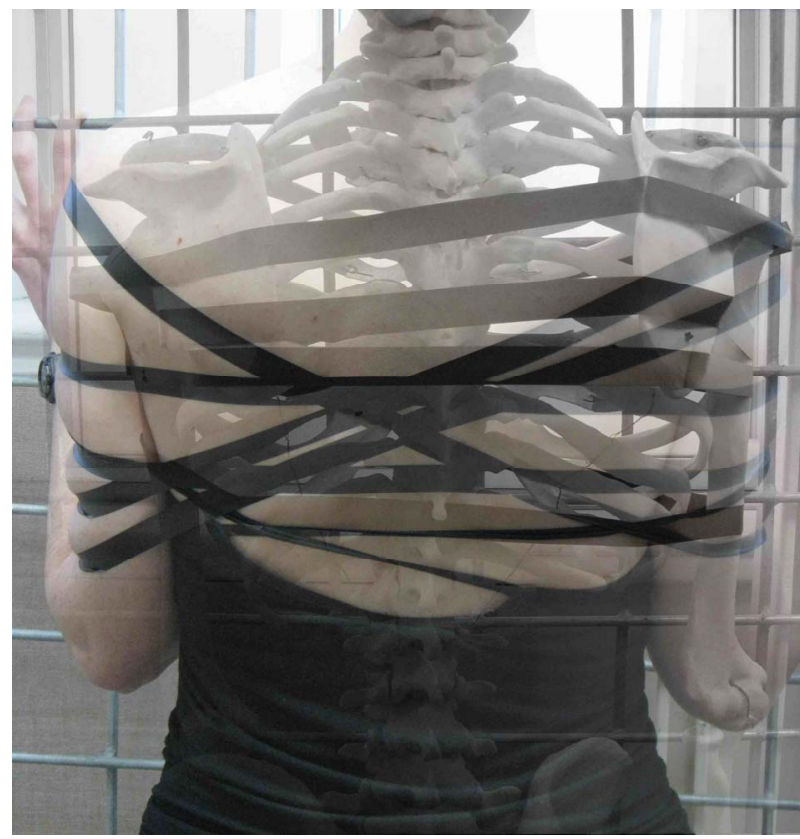

Figure 1.

Student created pain image A.

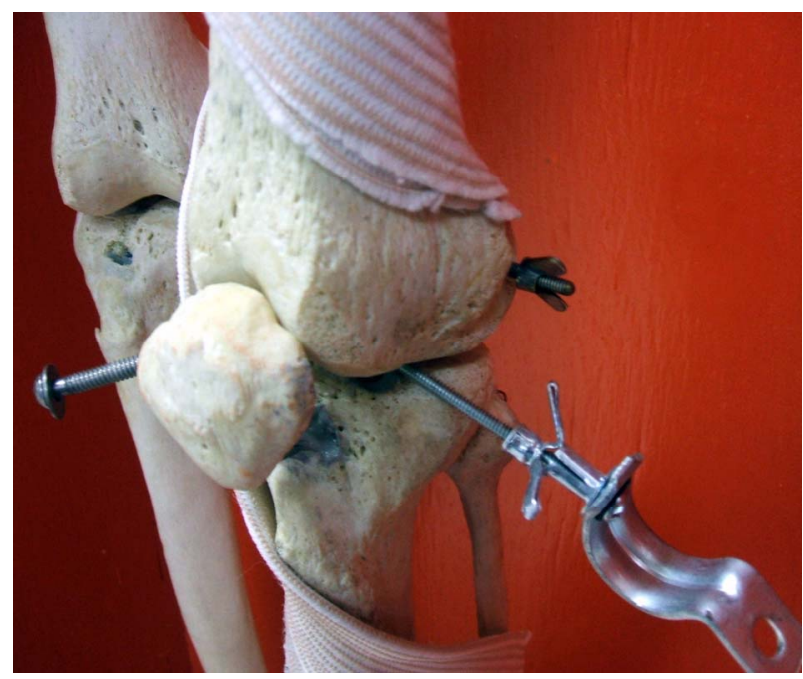

Figure 2.

Student created pain image 2.

depict that experience.

Complexity was enhanced as the professional artist involved in the module was able to challenge students to explore deeply and move beyond existing skill sets. The complex and demanding nature of the task required students to form relationships so as to assist each other in the many technical and physical components of the task. It was additionally challenging because of the cognitive-emotional elements of depicting feelings by the process of creating and editing digital images.

A consistent complexity that ran through all aspects of the two days was the cognitive-emotional demand of moving between two roles. The first role was participating in the activity of creating images to express one's own pain. The student then often needed to step back into the role of a therapist and think from that perspective about what therapeutic potential the activity provided and for which patient populations. Lastly, the sense of community was fostered by a closing meditation/reflection exercise lead by the visiting artist at the end of each day. To maintain the learning community links after the module was completed, the faculty member prepared a large poster for display in the Department with the images students had given written consent to use. A group portrait, including the visiting artist, was also displayed alongside the images.

\section{Linking the Experience to Theory}

The students' assignment for the module was to carry out a theory-focused activity analysis (Crepeau, 2003). The theory-focused activity analysis (TFAA) guided the students in thinking about the link between theory and practice and how to look at therapeutic activities from multiple theoretical perspectives (for example, biomechanical, Model of Human Occupation, rehabilitation) (Hagedorn, 2000). Each pair of students completed two TFAAs. One of the TFAAs had to be from a biomechanical perspective, the other was of their choosing. The instructor selected the very straightforward approach of biomechanics so as to build first year students' confidence and consolidation of the basic science knowledge they had recently mastered.

The second TFAA was from any theoretical perspective the students felt was appropriate. This choice allowed students to demonstrate exploration, creativity, and higher level integration of course content. The TFAA required students to name the practice theory; explain how that theory defines function, dysfunction, and change; and discuss both grading and adapting the activity from the perspective of the selected theory.

\section{Findings}

Most of the student pairs chose to use either the Canadian Model of Occupational Performance and Engagement (CMOP-E) (Townsend \& Polatajko, 2007) or the Model of Human Occupation (MOHO) (Kielhofner, 2008), and they were free to select an author within the foundational occupational therapy literature of their choice to define the pre-assigned biomechanical perspective.

\section{Learning Outcomes}

This section draws on examples from the students' assignments to illustrate how they achieved the learning goals and outcomes. The quotations (labeled Student 1 through 4) come from the students who are co-authors of this paper. At the time of writing there was no plan to prepare a manuscript and the students wrote without the bias of possible authorship. Other statements are composites of similar comments made by several students. As such, they are not directly attributable to any one student and breaches of confidentiality were avoided.

Students' assignments demonstrated their ability to complete a TFAA and, in more advanced students, to compare and contrast the two different theories. For example, students were comprehensive in reviewing the biomechanical demands of the activity.

- ...Ambulation and ascending and descending stairs were 
necessary to relocate to environments of interest to get the right backdrop for the photograph. In order to descend and ascend the stairs, muscles responsible for hip flexion, knee flexion, dorsi-flexion, hip extension, knee extension, and plantar flexion were necessary. As well, to hold on to the railing and maintain balance, shoulder abductors, elbow flexors and extensors, finger flexors and extensors, as well as the postural muscles were necessary. In order to walk, the muscles mentioned previously for stair climbing, as well as those responsible for trunk rotation and shoulder flexion and extension were necessary. This task required a higher level of muscle strength of a 4-as the muscles were working to move through less than half the range of motion against gravity and the resistance created by my body weight (Student 1).

- The individual would need to be able to endure standing, squatting, and sitting. These activities may need to be done while carrying varying weights (depending on the props) for a varying amount of time (depending on how long it takes to set things up and take the picture). Light activities for a $70 \mathrm{~kg}$ person such as standing require approximate 2 METs or $140 \mathrm{Kcals} / \mathrm{hour}$; sitting would require approximately $1.4 \mathrm{METs}$ or $100 \mathrm{Kcal} / \mathrm{hr}$. Photography, I believe, can be classified as a light activity, which according to the classification would require approximately 50 to $200 \mathrm{KCals}$ per hour for a $70 \mathrm{~kg}$ person (Student 2).

Students were able to apply the theoretical principles of biomechanics to identify opportunities for both adapting and for grading the demands of the activity:

- Equipment such as scissors as well as paper thicknesses could also be used to develop strength ... If the client had difficulties in fine motor movements, camera settings where the digital camera takes the photograph on a timer, or a tripod could be used (Student 1).

- By gradually increasing the weight of the camera or even the weight of the props that need to be manipulated, the client can increase their strength as well as their structural stability (Student 2).

Students were also able to discuss the limitations and relative merits of the biomechanical perspective.

- ...the biomechanical approach does not consider client's interests, cognition, motivation, or levels of pain. Therefore, this approach to activity analysis is not ideal, as the activity of expressing pain through art is a highly personal activity which involves a high degree of emotional and psychological aspects which are ignored by this model (Student 1).

Students proved equally capable when applying other theoretical perspectives. Student 3 reflected on the environment, as defined by the MOHO (Kielhofner, 2008) in relation to her performance of the photography task.

- The social environment included the instructors, my partner, and other classmates. These factors influenced my motivation, interpretation, and performance of the activity. After seeing what images others were creating, I was motivated to work harder at my image in order to meet the high standards that were being set. Interpretations of my image from others also influenced how I interpreted my own image and how I altered it.

Students articulated an appreciation for multiple perspectives so as to best match the therapeutic approach with the desired outcomes.

- Through the activity analysis with the biomechanical and MOHO theoretical approaches, we have an understanding of the complex nature of the activity of creating an art piece to express pain (Students 1 and 3).

- Not only can this activity address physical limitations, it also has the potential to employ and challenge occupational participation, the environmental and the personal (emotional, cognitive and spiritual) faculties (Students 2 and 4).

And lastly, students were overwhelmingly positive in their comments about this type of learning activity where personal lived experience forms a foundation for developing clinical skills and insights. The following comments are paraphrased from the feedback students provided at the completion of the module:

- I hope to encounter more learning opportunities like this during my training

- I am strongly motivated to learn more about the subject

- It increased my understanding of the subject, especially through the personal projects

- It was an advantage to have both the science/models and the art parts of expression being combined in such a way One of the student co-authors of this paper wrote the following reflection on what it was like to use personal lived experience with pain as part of the learning activity.

- Given that the experience of depicting pain through photography was personal, it allowed me to get a better appreciation of what my client may be going through. Not only did this experience afford me the opportunity to develop a stronger sense of empathy for my client, but it also allowed me to brainstorm of ways to modify and grade the activity from a therapist's perspective (Student 4).

\section{Discussion and Conclusion}

We believe that this theoretical perspective article has met both of our original aims. Specifically, we determined that situated learning opportunities can be afforded in the course modules required in the curriculum. Additionally, there is evidence from the students' work cited in this paper to support our conclusion that the module met the learning objective of developing scholarship and ability to apply theory-informed practice.

Much has changed in the 30 years plus since Shapiro and Shanahan (1976) raised the concern about how educators can develop teaching and learning strategies that help occupational therapy students, ultimately practitioners, to value scholarship and theory-informed practice. We now have access to a vast array of educational technologies and have a diverse range of robust theoretical constructs upon which to build. Additionally, in many countries, our students are no longer undergraduates but rather enter the profession at the graduate entry masters level or clinical doctorate. And yet, the profession's struggle to both value and build capacity in theory-informed practice reverberates across this period of time.

We believe that Vygotsky's (1962) concept that Most Knowledgeable Others have a strong influence on the values and practices of novice therapists holds important lessons for occupational therapy educators. Shapiro and Shanahan (1976) concluded their discussion of teaching theoretical concepts with a quote from Vygotsky on the nature of effective learning de- 
sign. Thirty years and many professional advancements later, his words are still relevant. "A teacher who tries to do this [present facts] usually accomplishes nothing but empty verbalism, a parrot-like repetition of words, simulating a knowledge of the corresponding concepts, but actually covering up a vacuum” (Vygotsky, 1962: p. 83).

These are both challenging and exciting days in education and we look forward to the ongoing dialogue needed to insure we continue to move towards theory-informed practices while still maintaining the best of intentions for our students.

\section{Acknowledgements}

We would like to acknowledge the contribution to this paper made by the other class members who participated in the module, the assistance of Robyn Berry in preparing this manuscript, and, particularly, the unique skills and vision brought to the experience by the artist, Deborah Padfield. We would like to thank the Canadian Pain Society and SEARCH Canada for providing financial assistance for Deborah Padfield's visit to Canada.

\section{References}

American Occupational Therapy Association (AOTA) (2009). Scholarship in occupational therapy. American Journal of Occupational Therapy, 63, 790-796. doi:10.5014/ajot.63.6.790

Canadian Association of Occupational Therapy (CAOT) (2011). Frequently Asked Questions by Employers and Government. URL (Last checked 23 March 2011)

http://www.caot.ca/default.asp?pageid=3910.

Crepeau, E. (2003). Analyzing occupation and activity: A way of thinking about occupational performance. In E. Crepeau, E. Cohen, \& B. Schell (Eds.), Willard \& Spackman's occupational therapy (pp. 189-202). Philadelphia: Lippincott Williams \& Wilkins.

Hagedorn, R. (2000). Tools for practice in occupational therapy: A structured approach to core skills and processes. London: Churchill Livingstone.

Hammel, J., Finlayson, M., Kielhofner, G., Helfrich, C., \& Peterson, E. (2002). Educating scholars of practice: An approach to preparing tomorrow's researchers. Occupational Therapy in Health Care, 15, 157-176. doi:10.1300/J003v15n01_15

Ikiugu, M., Smallfield, S., \& Condit, C. (2009). A framework for combining theoretical conceptual practice models in occupational therapy. Canadian Journal of Occupational Therapy, 76, 162-170.

Kielhofner, G. (2005). Scholarship and practice: Bridging the divide. American Journal of Occupational Therapy, 59, 231-239.

Kielhofner, G. (2008). Model of human occupation: Theory and application. Philadelphia, NA: Lippincott Williams \& Wilkins.

Knowledgebase, L. T. (2009). Situated Learning Theory (Lave) at Learning-Theories.com. (Last checked 23 March 2011)

http://www.learning-theories.com/situated-learning-theory-lave.html

Padfield, D., \& Hurwitz, B. (2003). As if... visualizing pain. International Journal of Epidemiology, 32, 704-707. doi:10.1093/ije/dyg283

Padfiled, D., Janmohamed, F., Zakrzewska, J., Pither, C., \& Hurwitz, B. (2010). A slippery surface... can photographic images of pain improve communication in pain consultations? International Journal of Surgery, 8, 144-150. doi:10.1016/j.ijsu.2009.11.014

Reed, K. (1984). Understanding theory: The first step in learning about research. American Journal of Occupational Therapy, 38, 677-682.

Rolfe, G., Freshwater, D., \& Jasper M. (2001). Critical reflection for nursing and the helping professions: A user's guide. London: Palgrave Macmillan.

Schon, D. (1983). The reflective practitioner. New York, NY: Basic Books.

Shapiro, D., \& Shanahan, P. (1976) Methodology for teaching theory in occupational therapy basic professional education. American Journal of Occupational Therapy, 30, 217-224.

Stein, D. (1998). Situated learning in adult education. ERIC Digests. (Last checked 23 March 2011) http://www.ericdigests.org/1998-3/adult-education.html

Townsend, E., \& Polatajko, H. (2007). Enabling occupation II: Advancing an occupational therapy vision for health, well-being, \& justice through occupation. Ottawa: CAOT Publishers.

Van Deusen, J. (1986). Occupational therapy theory: Values held by undergraduate students. Occupational Therapy Journal of Research, 6, 115-122.

Vygotsky, L. (1962). Thought and language. Cambridge: MIT Press. doi:10.1037/11193-000

Wertsch, J., \& Sohmer, R. (1995). Vygotsky on learning and development. Human Development, 38, 332-337. doi:10.1159/000278339 